\title{
THE NATURAL DESIGN OF HIERARCHY: BASKETBALL VERSUS ACADEMICS
}

\author{
A. BEJAN \& P. HAYNSWORTH \\ Duke University, Department of Mechanical Engineering and Materials Science, Durham, NC, USA
}

\begin{abstract}
The power-law correlation between frequency and rank is a physics characteristic of natural flow systems (river basins, demography) in accordance with the constructal law. Here we show that this robust characteristic is a consequence of their design as area-point and point-area flow systems that morph freely and compete for access on an area. The emergence of hierarchical design is illustrated with the rankings of university basketball programs. Although basketball rankings have the same character as the university rankings, there is no correlation between the two rankings. Academic excellence and basketball excellence are two different flow architectures on the same area, like the flow of humanity (demography) and the flow of water (river basins). Together, they show how the evolution of sports allows us to witness biological evolution in our life time.

Keywords: constructal law, hierarchy, basketball rankings, university rankings, design in nature.
\end{abstract}

Mens sana in corpore sano

(A healthy mind in a healthy body)

\section{THE EVOLUTION OF SPORTS}

Why is it that when we watch the National Collegiate Athletic Association (NCAA) basketball tournament we always see the same schools? It seems that there are a few university basketball programs that are always successful while many more continually struggle. Here we show why this must be so and why this pattern - the ranking of college basketball - will not change much in the future. In short, basketball is a form of education that flows on the globe with hierarchal channels, like all river basins.

To pose a question about the ranking of basketball programs in a scientific journal may surprise the reader. We have several reasons for framing the question in these terms. First, the evolution of sports is a widely recognized phenomenon that only recently has become a laboratory in which to predict biological evolution and witness it in our lifetime. Starting from the constructal law, we predicted that the speed sports (run and swim) should evolve toward faster athletes who are bigger, taller, and with bodies that are more slender [1]. In addition, we explained why the sprint favors athletes with bodies with high centers of gravity, while speed swimming favors bodies with low centers of gravity (i.e. with longer torsos) [2]. The science of sports evolution represents a significant step in evolutionary biology, while the accepted view in biology is that evolution is impossible to observe because of its extremely long characteristic time. With sports, we focus on a particular population of athletes and we witness 'live' the evolution of the design and performance of the selected group.

Second, 'rankings' abound in the design of nature; in fact, they underpin what is commonly described as diversity, multiple scales and complexity. This overriding natural phenomenon has been noted, and is being described empirically as hierarchies, allometric scaling and distributions of frequency versus rank, for example in language, computing, information, demography [3], river basin design [4], the tree of life [5]. Before the constructal law [3, 4], predicting the occurrence of these distributions had been impossible, as demonstrated by Fontanari and Perlovski [6]. With the constructal law, the distribution of frequency versus rank was predicted based on physics (the constructal law) for two natural flow architectures: the hierarchical distribution of human settlements (Fig. 1) and the hierarchy of tree sizes and numbers in all forests [7] (Fig. 2). 


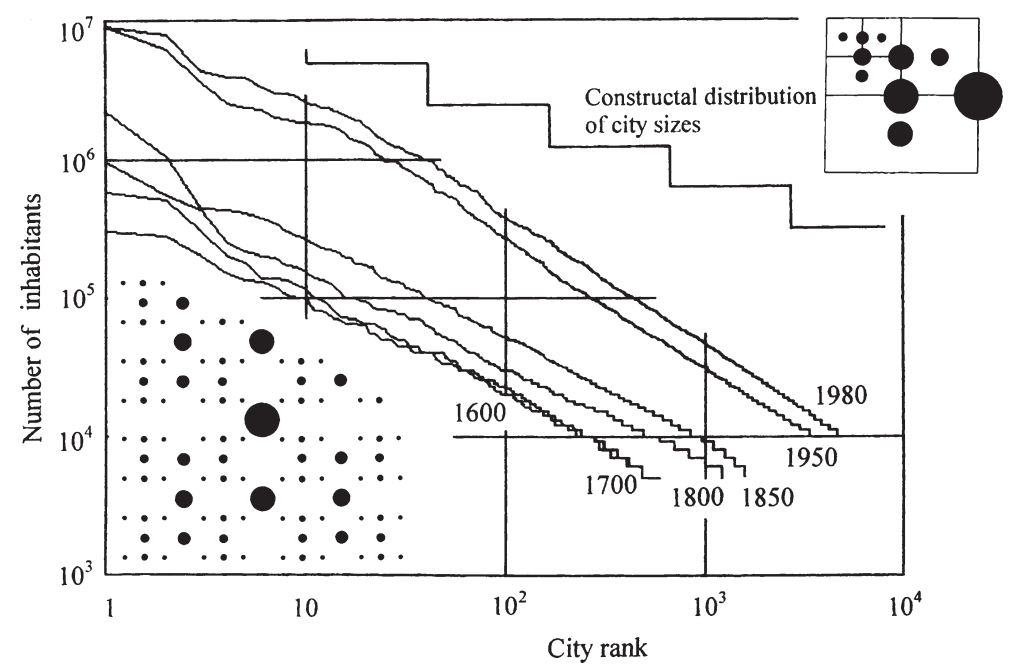

Figure 1: City sizes versus rank in Europe during 1600-1980, and the size-rank distribution predicted with the constructal law [3].

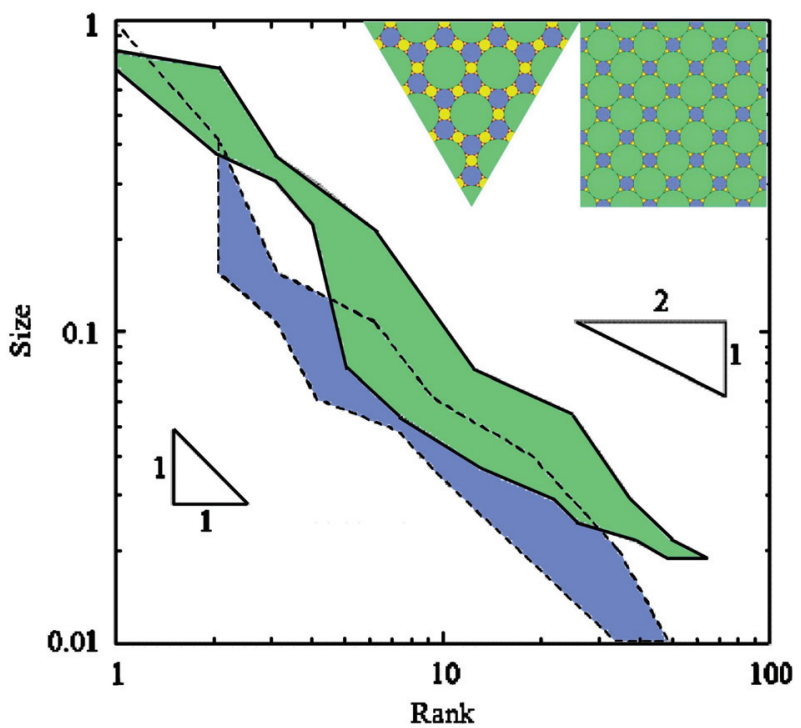

Figure 2: Distribution of tree canopy sizes versus rank in the constructal design of the forest floor [7]. The distribution is insensitive to the pattern (e.g. triangular vs. square) in which the multiscale tree canopies are arranged on the forest floor.

Third, evolution and hierarchical designs are not restricted to the domain that is usually assigned to biology. These features are also the body of the design phenomenon in geophysical (inanimate) systems (e.g. river basins, cf. Bejan and Marden [8]) and social dynamics [9]. An example of social dynamics with hierarchy is the ranking of universities according to their numbers of researchers on the highly cited list $[10,11]$ (Fig. 3). The reason that universities rank themselves in the same way 


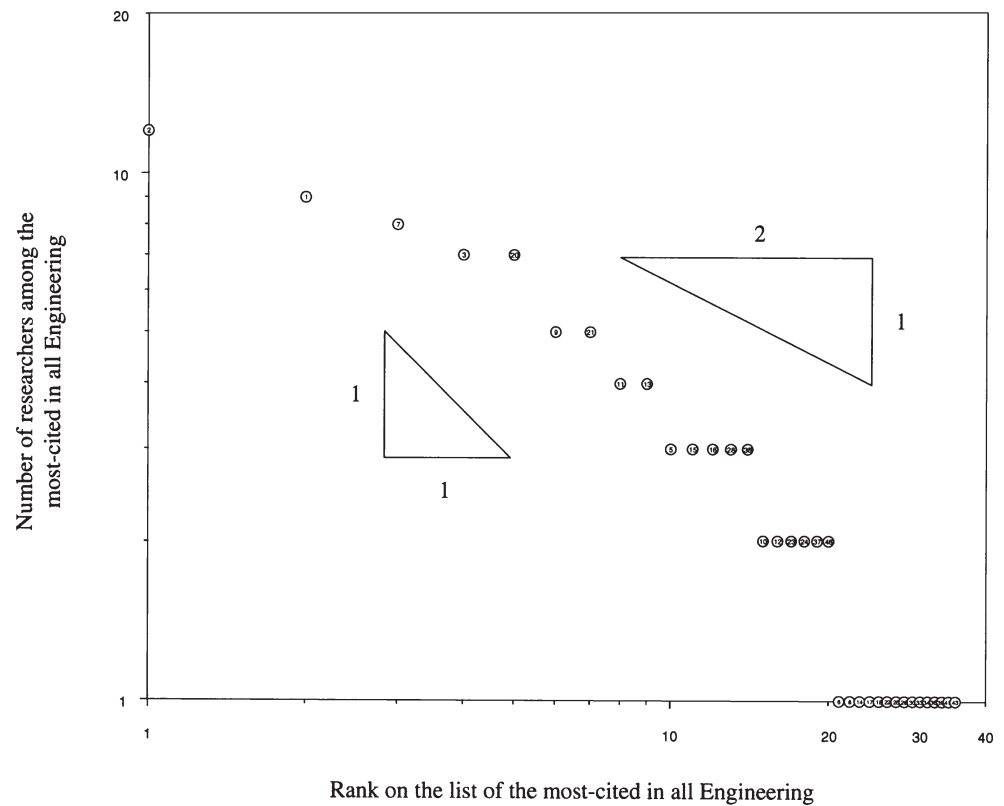

Figure 3: The distribution of universities ranked according to their numbers of researchers on the highly cited list in all engineering disciplines [10].

as other natural (freely morphing) flow systems is that education sweeps the globe like the river basins and all the other hierarchical designs. The same principle accounts for the natural selforganization of any research institution into a few large groups (research empires) and many individual researchers [12], and the emergence of dark (invisible) networks that guide the flow of individuals and groups in academia [13].

Education covers all forms of transfer of knowledge. It is a global flow vasculature composed of a very large number of flow networks that connect the few who know with the many who need to know. The few are points on areas inhabited by the many. The points and their allocated areas are linked on the geography of the flow system. These paths are tree-shaped. They are analogous to other natural point-area and area-point networks, river basins, deltas, lungs, urban traffic, and living tissues. All these designs are hierarchical, with links and channels that can be summarized as "few large and many small' [14]. The necessary presence of the few large is due to the constructal-design feature that larger flow systems are more efficient [15] and cover larger territories [14].

Collegiate basketball programs are one education flow system-one among many. They are akin to engineering, English literature, and business programs. Basketball programs are much better known to the general public than the academic programs that thrive on campuses. College basketball is featured on television, it is written about in magazines and the internet, and it is talked about amongst students, alumni and fans. For this reason we propose to explain in terms of basketball rankings the origin and permanence of frequency-rank distributions in natural, freely morphing flow systems.

\section{THE PERMANENCE OF HIERARCHY IN NATURAL FLOW DESIGNS}

The flows of nature evolve in time to flow more easily, in accordance with the constructal law: 'For a finite-size flow system to persist in time (to live) its configuration must change in time such that it provides greater and greater access to its currents' [16]. They achieve this ever improving quality 
through the generation of flow configurations. Existing designs (literally drawings on the map) are replaced by new designs that flow more easily. Societal tree flows emerge in the same way as the trees of the river basins: to provide greater and greater access, in time.

In this phenomenon of design generation and evolution the age of the flow structure matters, and it is good for flow performance. The river basin digs its channels better and better, and the channels stay in place. The channels have hierarchy: a few large channels flow in harmony with many small channels. A new rainy season is served well by the 'memory' built into the old river beds.

Societal flows exhibit the same design phenomenon. Education flows through a vascularized landscape of universities, each university being connected to the entire globe. The older and better universities have dug their channels earlier, and these are some of the largest channels that irrigate the knowledge landscape. 'Largest' does not mean largest numbers of bodies flowing through classrooms and locker rooms. Largest are the streams of the most famous and the best- the mentors, the ideas, and the disciples (cf.[14, 15]). Largest are the channels that attract those who cultivate the new knowledge and new talent. Each new generation of students and players is served well by the memory built into the education flow design.

\section{THE PERMANENCE OF COLLEGE BASKETBALL HIERARCHY}

The ranking of universities is demanded by the need of large numbers of students and educators to facilitate the flow of education, along the most accessible routes that cover an area, like a river basin. The hierarchy of channels in a river basin does not change from season to season. From this view followed the prediction that the hierarchy of universities should not change [10,11]. The hierarchy itself comes from the same mental viewing. Examine the sketch in the upper-right corner of Fig. 1. On every elemental area $\left(A_{i}\right.$, shown as a white rectangle) there are two populations: a number of people $\left(\mathrm{N}_{\mathrm{i}, \mathrm{A}}\right)$ who inhabit and work on $\mathrm{A}_{\mathrm{i}}$ (e.g. farmers) and a number $\left(\mathrm{N}_{\mathrm{i}, \mathrm{c}}\right)$ who live in a human settlement (village, town, city), which is shown as a black disc. We make two observations:

1. Because the two groups are linked by flows in both directions, point-area and area-point, and because the flows are of many types (people, goods, technology, education, etc.), the numbers $\mathrm{N}_{\mathrm{i}, \mathrm{A}}$ and $\mathrm{N}_{\mathrm{i}, \mathrm{c}}$ must be proportional. One group sustains the other, and vice versa.

2. The population living on land must be proportional to the land area, $\mathrm{N}_{\mathrm{i}, \mathrm{A}}=\mathrm{cA}_{\mathrm{i}}$. The land sustains the population $\mathrm{N}_{\mathrm{i}, \mathrm{A}}$, and vice versa. The proportionality constant $\mathrm{c}(\mathrm{t})$ increases in time because the technology that assists the $\mathrm{N}_{\mathrm{i}, \mathrm{A}}$ population improves in time.

Putting these two observations together, we anticipate that the size of the settlement $\left(\mathrm{N}_{\mathrm{i}, \mathrm{c}}\right)$ must be proportional to $\mathrm{cA}_{\mathrm{i}}$. This means that the size of a city is dictated by the populated area with which that city is connected.

Next, a larger inhabited land (state, country, continent) can be viewed as a construction in which larger area elements are made with smaller area elements that serve as building blocks. Each larger area has its area $\mathrm{A}_{\mathrm{j}}$, and populations $\mathrm{N}_{\mathrm{j}, \mathrm{A}}$ and $\mathrm{N}_{\mathrm{j}, \mathrm{c}}$. The size of the settlement reflects the size of its area, and as shown in the lower-left corner of Fig. 1, when the construction lines are erased, the landscape appears to be covered by a multi-scale distribution of human settlements, few large and many small. When counted and ranked, the predicted distribution of the settlements is a straight line that reveals the distribution of European cities throughout modern history. In addition, this theoretical line must shift upward in time, because the factor $\mathrm{c}(\mathrm{t})$ increases from one technological era to the next.

The city rankings (Fig. 1) and university rankings (Fig. 3) owe their existence and robustness to this geographical tapestry of area-point and point-area flows of multiple sizes. The ranking of 
college basketball is just as rigid. The movement of basketball players from high school to the professional level is a flow with its own architecture. There are over 23,000 high schools in the United States of America. Practically all have basketball teams. The talent ranges from those who would never dream of playing basketball in college to those who aspire to the National Basketball Association (NBA). A few years ago the NBA instituted a minimum age rule, requiring players to be 19 before entering the NBA draft. As a result, basketball players are essentially forced to choose a university path to the NBA. There are 330 Division I basketball programs that channel players to $30 \mathrm{NBA}$ teams. The high schools and universities are tributaries to the big river that leads to the NBA.

Figure 4 shows how the top university basketball programs arrange themselves when ranked according to their total number of appearances in the Final Four of the NCAA Tournament (the Final Four is the semi-final round of the annual national university championship) [17, 18] (Table 1). When plotted on a log-log field the data trace a nearly straight line with a descending slope. This feature is important because it unites all natural flow systems that cover the land (e.g. Figs 1-3). This distribution is a characteristic of the organization of all flow systems that morph freely and compete for access on the same finite-size territory.

The ranking of the top teams tells a similar story when the measure is the number of players that each team sent to the NBA during 1949-2007 [19] (Table 2). These data are plotted log-log in Fig. 5, and their alignment is the same as in Fig. 4. This conclusion is reinforced by Fig. 6, in which we cross-plotted the two rankings (Figs 4 and 5) as one abscissa against the other. There is a correlation between success in the Final Four Tournament and success in sending players to the NBA. The cloud of data embraces the rising diagonal, and the scatter diminishes greatly in the lower-left corner, i.e. at the top of the rankings. The more successful NCAA teams serve as larger and faster streams to the NBA. In conclusion, the hierarchy is not only rigid but also relatively insensitive to the criterion used making the ranking.

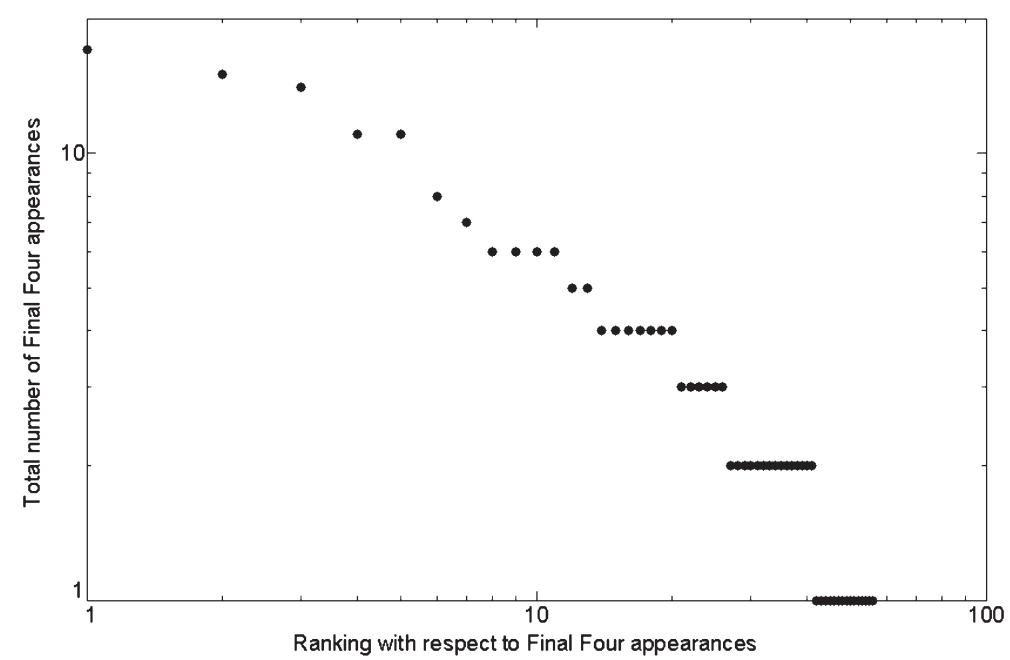

Figure 4: The number of appearances in the Final Four of the NCAA Tournament versus the rank of each team on that list (data from Table 1). 
Table 1: Ranking of basketball programs according to total number of Final Four Appearances in the NCAA Tournament in the history of each basketball program [17].

\begin{tabular}{|c|c|c|}
\hline Rank & School & $\begin{array}{c}\text { Final Four Appearances in the } \\
\text { NCAA Tournament }\end{array}$ \\
\hline 1 & UCLA & 17 \\
\hline 2 & North Carolina & 15 \\
\hline 3 & Duke & 14 \\
\hline 4 & Kentucky & 11 \\
\hline 5 & Kansas & 11 \\
\hline 6 & Louisville & 8 \\
\hline 7 & Indiana & 7 \\
\hline 8 & Michigan State & 6 \\
\hline 9 & Michigan & 6 \\
\hline 10 & Cincinnati & 6 \\
\hline 11 & Ohio State & 6 \\
\hline 12 & Illinois & 5 \\
\hline 13 & Houston & 5 \\
\hline 14 & Arizona & 4 \\
\hline 15 & Syracuse & 4 \\
\hline 16 & LSU & 4 \\
\hline 17 & Georgetown & 4 \\
\hline 18 & UNLV & 4 \\
\hline 19 & Florida & 4 \\
\hline 20 & Arkansas & 4 \\
\hline 21 & NC State & 3 \\
\hline 22 & Marquette & 3 \\
\hline 23 & Utah & 3 \\
\hline 24 & Iowa & 3 \\
\hline 25 & San Francisco & 3 \\
\hline 26 & Kansas State & 3 \\
\hline 27 & St. John's & 2 \\
\hline 28 & Maryland & 2 \\
\hline 29 & Georgia Tech & 2 \\
\hline 30 & Villanova & 2 \\
\hline 31 & Connecticut & 2 \\
\hline 32 & Providence & 2 \\
\hline 33 & Temple & 2 \\
\hline 34 & Memphis & 2 \\
\hline 35 & Purdue & 2 \\
\hline 36 & Oregon State & 2 \\
\hline
\end{tabular}


Table 1: Continued

\begin{tabular}{|c|c|c|}
\hline 37 & Oklahoma & 2 \\
\hline 38 & California & 2 \\
\hline 39 & LaSalle & 2 \\
\hline 40 & Bradley & 2 \\
\hline 41 & Virginia & 2 \\
\hline 42 & Notre Dame & 1 \\
\hline 43 & Minnesota & 1 \\
\hline 44 & DePaul & 1 \\
\hline 45 & Texas & 1 \\
\hline 46 & USC & 1 \\
\hline 47 & Wake Forest & 1 \\
\hline 48 & Stanford & 1 \\
\hline 49 & Florida State & 1 \\
\hline 50 & Georgia & 1 \\
\hline 51 & Western Kentucky & 1 \\
\hline 52 & Washington & 1 \\
\hline 53 & Mississippi State & 1 \\
\hline 54 & Seton Hall & 1 \\
\hline 55 & UTEP & 1 \\
\hline 56 & Dayton & 1 \\
\hline 57 & Alabama & 0 \\
\hline 58 & Missouri & 0 \\
\hline 59 & Arizona State & 0 \\
\hline 60 & Tennessee & 0 \\
\hline 61 & Oregon & 0 \\
\hline 62 & Boston College & 0 \\
\hline 63 & BYU & 0 \\
\hline 64 & Long Beach State & 0 \\
\hline 65 & Fresno State & 0 \\
\hline 66 & Iowa State & 0 \\
\hline 67 & South Carolina & 0 \\
\hline 68 & Clemson & 0 \\
\hline 69 & Xavier & 0 \\
\hline 70 & Auburn & 0 \\
\hline
\end{tabular}

\section{HIERARCHY IS PATTERN AND DIVERSITY, IN BALANCE}

The robustness exhibited by university rankings contradicts the appealing argument that rankings depend on the formula used to calculate the rank. Why the two points of view have merit is explained by the fact that the hierarchy of natural point-area flows has two main features, pattern and diversity. These features are evident in the distribution of tree sizes and numbers in the forest, and the distribution of cities on a continent. They are also present in Figs 3-6. The scatter represents the 'diversity', which is located primarily in the lower ranks, where there are many competitors for the same rank. It is for this large group that the chosen formula matters, but it matters little. 
Table 2: Ranking of Basketball programs according to total number of players drafted into the NBA (1949-2007) [18].

\begin{tabular}{|c|c|c|}
\hline Rank & School & Number of players drafted into the NBA \\
\hline 1 & UCLA & 48 \\
\hline 2 & North Carolina & 46 \\
\hline 3 & Duke & 40 \\
\hline 4 & Indiana & 40 \\
\hline 5 & Arizona & 35 \\
\hline 6 & Louisville & 35 \\
\hline 7 & Kentucky & 34 \\
\hline 8 & St. John's & 32 \\
\hline 9 & Maryland & 30 \\
\hline 10 & Kansas & 28 \\
\hline 11 & Illinois & 27 \\
\hline 12 & Syracuse & 27 \\
\hline 13 & Michigan State & 26 \\
\hline 14 & Georgia Tech & 26 \\
\hline 15 & Notre Dame & 26 \\
\hline 16 & Michigan & 26 \\
\hline 17 & NC State & 25 \\
\hline 18 & Cincinnati & 24 \\
\hline 19 & Ohio State & 24 \\
\hline 20 & LSU & 24 \\
\hline 21 & Minnesota & 24 \\
\hline 22 & Alabama & 24 \\
\hline 23 & Villanova & 22 \\
\hline 24 & Connecticut & 21 \\
\hline 25 & DePaul & 20 \\
\hline 26 & Houston & 20 \\
\hline 27 & Missouri & 19 \\
\hline 28 & Providence & 19 \\
\hline 29 & Marquette & 19 \\
\hline 30 & Georgetown & 19 \\
\hline 31 & Utah & 19 \\
\hline 32 & Texas & 18 \\
\hline 33 & USC & 18 \\
\hline 34 & Wake Forest & 18 \\
\hline 35 & UNLV & 18 \\
\hline 36 & Iowa & 18 \\
\hline 37 & Arizona State & 17 \\
\hline 38 & Temple & 17 \\
\hline 39 & Memphis & 16 \\
\hline
\end{tabular}


22 A. Bejan \& P. Haynsworth, Int. J. of Design \& Nature and Ecodynamics. Vol. 7, No. 1 (2012)

Table 2: Continued

\begin{tabular}{lll}
\hline 40 & Purdue & 16 \\
41 & San Francisco & 16 \\
42 & Oregon State & 16 \\
43 & Florida & 15 \\
44 & Stanford & 15 \\
45 & Tennessee & 15 \\
46 & Oregon & 14 \\
47 & Florida State & 14 \\
48 & Oklahoma & 14 \\
49 & Georgia & 14 \\
50 & Arkansas & 14 \\
51 & Kansas State & 14 \\
52 & Boston College & 13 \\
53 & California & 13 \\
54 & BYU & 13 \\
55 & Long Beach State & 13 \\
56 & Fresno State & 12 \\
57 & Iowa State & 12 \\
58 & South Carolina & 12 \\
59 & Western Kentucky & 12 \\
60 & Washington & 11 \\
61 & Mississippi State & 11 \\
62 & Seton Hall & 11 \\
63 & LaSalle & 11 \\
64 & Clemson & 11 \\
65 & Bradley & 11 \\
66 & UTEP & 11 \\
67 & Xavier & 10 \\
68 & Auburn & 10 \\
69 & Virginia & 10 \\
70 & Dayton & \\
\hline
\end{tabular}

To leapfrog a few racers in the peloton (the thick end of the cloud of data in Fig. 6) is to remain in place, inside the peloton. The runaway racers are well in front, and they have names. Their alignment on the diagonal (Fig. 7) represents the 'pattern'. This is hierarchy, and it transcends all the scheming that goes into ranking formulas and claims that a university (academics or basketball) can be redesigned to score higher in the rankings.

These features (frequency vs. rank, robustness, pattern and diversity) reinforce the physics view that basketball education is a flow system that sweeps the land (earlier over the USA alone, now over the globe) while constantly generating flow structures that are more and more efficient. In this evolving design, the top schools are the big branches. They are the few, not the many. Their identity is permanently carved into the geography of the global flow system. 


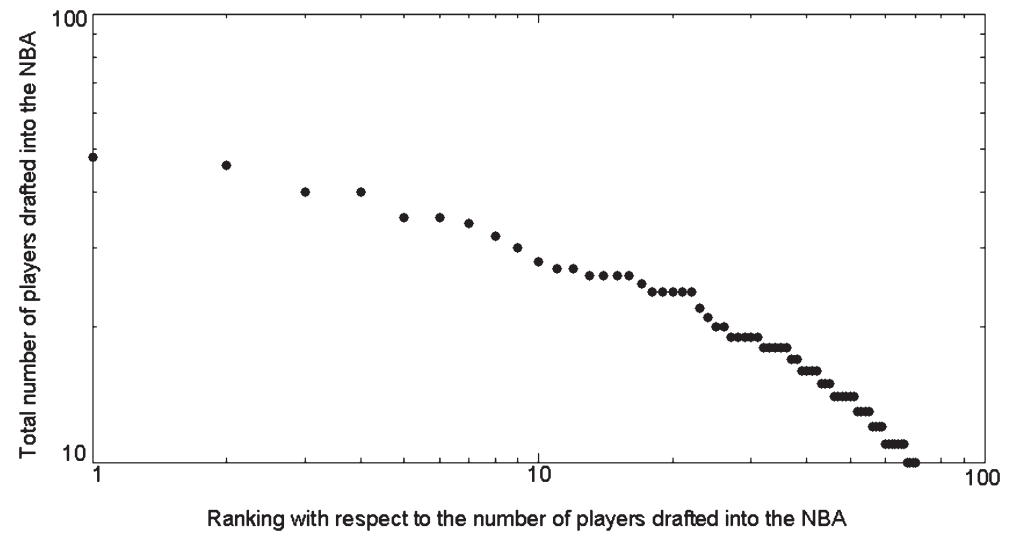

Figure 5: The number of players selected by the NBA from each team versus the rank of the team on that list (data from Table 2).

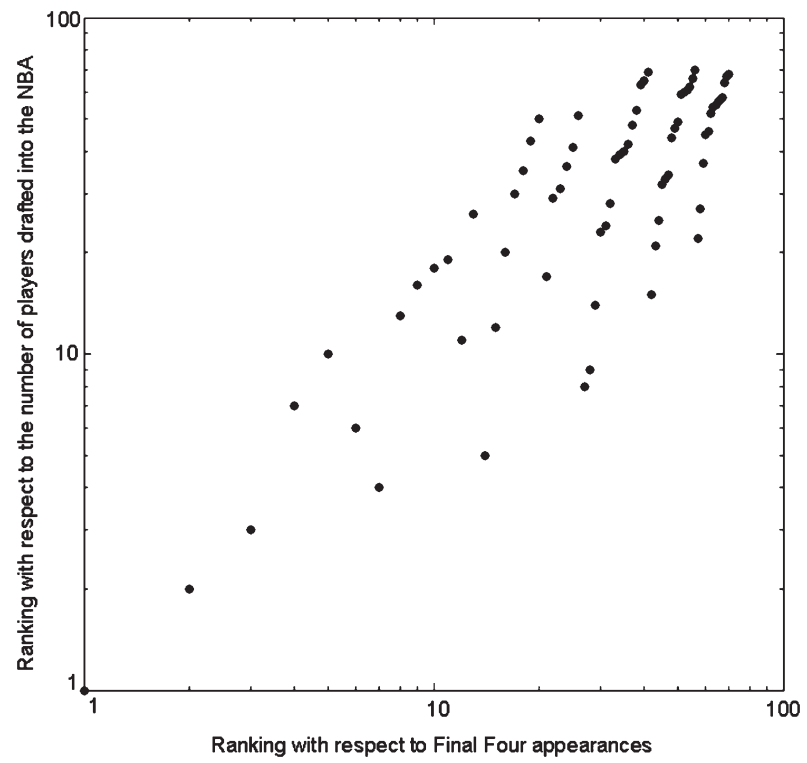

Figure 6: The robustness of hierarchy: the rank based on the number of players sent to the NBA (Fig. 5 abscissa) versus the rank based on the number of Final Four appearances (Fig. 4 abscissa).

\section{A HEALTHY MIND IN A HEALTHY BODY?}

Basketball is just one kind of education as a flow system on the landscape. Every other discipline in which training is pursued by students living on the same area is a flow system with lasting architecture, in which a few large channels flow in harmony with the many smaller channels. The large channels are the highways on which the faster and farther moving students travel.

If we superimpose on the global geography all the flow structures of the various disciplines, we begin to imagine how universities constitute their natural global design. The hierarchy of universities 


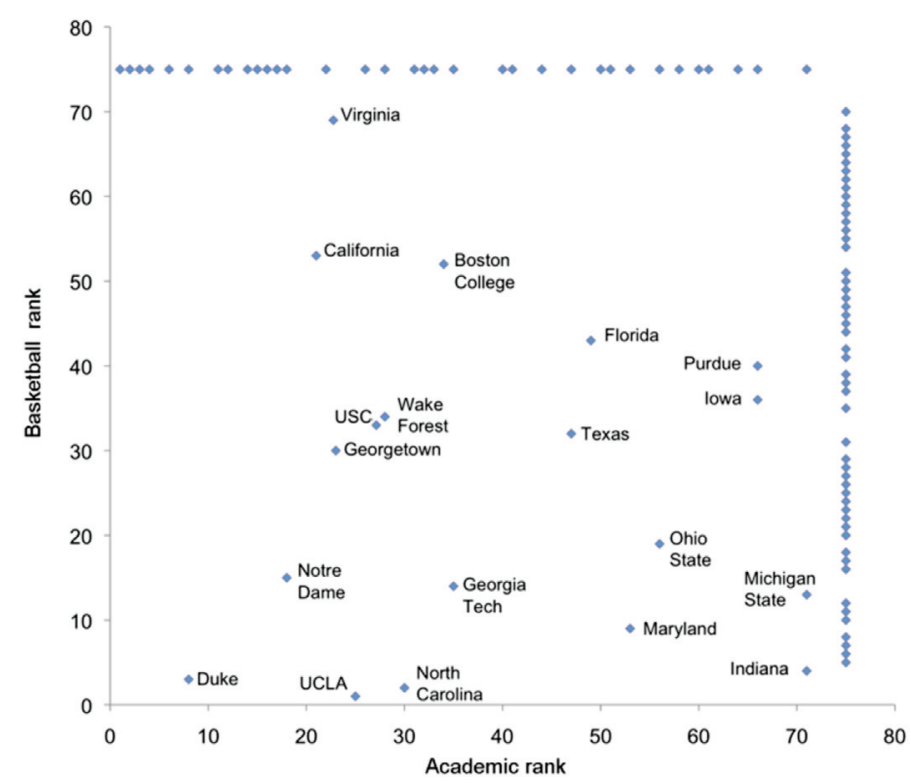

Figure 7: The ranking of universities according to US News \& World Report (x), versus the ranking according to the number of players drafted into the NBA (y). Most of the universities fall outside the $75 \times 75$ area: they are plotted on the sidelines (those with $x>75$ are plotted at $\mathrm{x}=75$, and those with $\mathrm{y}>75$ are plotted at $\mathrm{y}=75$ ).

is discussed intensely every year, and its permanence in time is predictable [10,11]. Consider now the comparison between the ranking of universities and the ranking of basketball programs (Fig. 7). There is no relation between the two rankings. Had they been related, their data would have fallen near the rising diagonal. Most of the universities appear only in one of the rankings. This is why most universities fall on the sidelines of Fig. 7. They separate themselves into two different worlds.

When educators and sports announcers refer to college players as 'scholar athletes' they misrepresent both worlds. 'Basketball students' is a more accurate name, as is 'engineering students' for those who study engineering. This stresses again the notion that the global flow of education is a superposition of evolving vasculatures associated with the various disciplines.

The channels of basketball excellence are not the same as the channels of excellence in academia. The two flow architectures have different histories, memories and channels. This dissonance is physics, and it is worth contemplating because it runs against one of the pillars of modern education: Mens sana in corpore sano (a healthy mind in a healthy body; from Juvenal's Satires). Modern education has been right to adopt this doctrine, because it works. Current research shows that exercise and brain function development go together [20,21].

The university design needs constant work, reminders and reinforcement, just like the dams that protect the city from the big river that passes through it. In particular, the message of the natural (constructal) design of hierarchy is that sports on campus require constant effort, i.e. constant work to improve its design and maintain its survival.

\section{ACKNOWLEDGEMENT}

A. Bejan and P. Haynsworth's research was supported by the National Science Foundation and the Department of the Navy, respectively. 


\section{REFERENCES}

[1] Charles, J.D. \& Bejan, A., The evolution of speed, size and shape in modern athletics. Journal of Experimental Biology, 212, pp. 2419-2425, 2009. doi: http://dx.doi.org/10.1242/ jeb.031161

[2] Bejan, A., Jones, E.C. \& Charles, J.D., The evolution of speed in athletics: why the fastest runners are black and swimmers white. International Journal of Design \& Nature and Ecodynamics, 5(3), pp. 199-211, 2010. doi: http://dx.doi.org/10.2495/DNE-V5-N3-199-211

[3] Bejan, A., Lorente, S., Miguel, A.F. \& Reis, A.H., Constructal theory of distribution of city sizes, Section 13.4 in A. Bejan, Advanced Engineering Thermodynamics, 3rd edition, Wiley: Hoboken, 2006.

[4] Bejan, A., Lorente, S., Miguel, A.F. \& Reis, A.H. Constructal theory of distribution of river sizes, Section 13.5 in A. Bejan, Advanced Engineering Thermodynamics, 3rd edition, Wiley: Hoboken, 2006.

[5] Herrada, E.A., Tessone, C.J., Klemm, K., Eguiluz, V.M., Hernandez-Garcia, E. \& Duarte, C.M., Universal scaling in the branching of the tree of life. PLoS One 3, pp. e2759, 2008. doi: http://dx.doi.org/10.1371/journal.pone.0002757

[6] Fontanari, J.F. \& Perlovsky, L.I., Solvable null model for the distribution of word frequencies. Phys. Rev. E, 70. pp. 042901, 2004. doi: http://dx.doi.org/10.1103/PhysRevE.70.042901

[7] Bejan, A., Lorente, S. \& Lee, J., Unifying constructal theory of tree roots, canopies and forests. Journal of Theoretical Biology, 254, pp. 529-540, 2008. doi: http://dx.doi.org/10.1016/j. jtbi.2008.06.026

[8] Bejan, A. \& Marden, J.H., The constructal unification of biological and geophysical flow design. Physics of Life Reviews, 6, pp. 85-102, 2009. doi: http://dx.doi.org/10.2495/DNE-V4N4-386-394

[9] Bejan, A. \& Merkx, G.W., eds. Constructal Theory of Social Dynamics, Springer: New York, 2007.

[10] Bejan, A. 2007. Why university rankings do not change: education as a natural hierarchical flow architecture. Int. J. Design \& Nature, 2, pp. 319-327.

[11] Hermes, J.J., Fixed rankings? The Chronicle of Higher Education, March 14, 2008.

[12] Bejan, A., Constructal self-organization of research: empire building versus the individual investigator. International Journal of Design \& Nature and Ecodynamics, 3(3), pp. 177-189, 2008.

[13] Bejan, A., Two hierarchies in science: the free flow of ideas and the academy. International Journal of Design \& Nature and Ecodynamics, 4(4), pp. 386-394, 2009.

[14] Lorente, S. \& Bejan, A., Few large and many small: hierarchy in movement on earth. International Journal of Design \& Nature and Ecodynamics, 5(3), pp. 254-267, 2010. doi: http://dx.doi.org/10.2495/DNE-V5-N3-254-267

[15] Bejan, A., Lorente, S., Yilbas, B.S. \& Sahin, A., The effect of size on efficiency: power plants and vascular designs. International Journal of Heat and Mass Transfer, 54(7-8), pp. 1475-1481, 2011.

[16] Bejan, A. Advanced Engineering Thermodynamics, 2nd edition, Wiley: New York, 1997.

[17] NCAA, All-Time Winningest Teams. National Collegiate Athletic Association. 15 April, http:// www.ncaa.org, 2007

[18] NCAA, Tournament History. ESPN.com, ESPN Internet Ventures, 2007.

[19] NBA, NBA Draft Picks by School. Rush the Court. 15 April 2008, http://www.rushthecourt. wordpress.com, 26 June 2007. 
[20] Cotman, C.W., Berchtold, N.C. \& Christie, L.-A., Exercise builds brain health: key roles of growth factor cascades and inflammation. Trends in Neurosciences, 30(9), pp. 464-472, 2007. doi: http://dx.doi.org/10.1016/j.tins.2007.06.011

[21] Liu, Y.-F., Chen, H.-I., Wu, C.-L., Kuo, Y.-M., Yu, L., Huang, A.-M., Wu, F.-S., Chuang, J.-I. \& Jen, C.J., Differential effects of treadmill running and wheel running on spatial or aversive learning and memory: roles of amygdalar brain-derived neurotropic factor and synaptotagmin I. Journal of Physiology, 587(13), pp. 3221-3231, 2009. doi: http://dx.doi.org/10.1113/ jphysiol.2009.173088 